\title{
LETRAS E LINGUÍSTICA NO CONTEXTO DA POLÍTICA CIENTÍFICA: CONHECER É HUMANIZAR
}

\author{
LETTERS AND LINGUISTICS IN THE CONTEXT OF SCIENTIFIC \\ POLICIES: TO KNOW IS TO HUMANIZE
}

\author{
Frederico Augusto Garcia Fernandes \\ Universidade Estadual de Londrina, Londrina, Paraná, Brasil \\ Presidente da ANPOLL \\ fredma@uel.br
}

Resumo: Esse artigo busca refletir sobre o protagonismo da área de Letras e Linguística numa política científica nacional. Ele debate os seguintes tópicos: a importância da diversidade de saberes na produção de conhecimento; a exclusão de temas das humanidades da política pública de financiamento, bem como o atual sistema de avaliação das agências de fomento, que estimula o "produtivismo".

Palavras-chave: Letras e Linguística; Pesquisa; Pós-Graduação; Política de Financiamento

Abstract: This article aims to ponder over issues concerning scientific policies related to Letters and Linguistics as a field of study in Brazil. It covers topics such as the importance of diversity of know-how in the production of knowledge; the exclusion of humanity issues in the public funding policy; as well as the current public funding agencies assessment system which stimulates a high production of publications.

Keywords: Letters and Linguistics; Research; Post-Graduation; Funding Policy 
Toda a ciência é humana

(Ato unificado em defesa das humanidades)

O que significa ser um cientista? Se fossem mostradas a foto de um pesquisador da cultura num arquivo e, depois, de outra pessoa examinando num microscópio e fosse sugerido a alguém apontar qual deles é o cientista, certamente seria indicado o segundo. Essa suposição inicial fundamenta-se no imaginário de que a ideia popularmente constituída de cientista encontra-se enraizada, ainda em nossa fase escolar, nos professores de química, física, biologia e não nos de língua portuguesa e literatura. Por isso, pesquisas sobre as variações linguísticas ou a formação de leitores, os limites da interpretação, as impossibilidades de tradução, a análise do discurso, os estudos sobre cultura, ideologia e gênero, geralmente, costumam não ser tomadas de imediato como ciência.

Em Uma história das Ciências Humanas, Jean-François Dortier (2009, p. 25), a partir do pioneiro trabalho sobre a relação entre o sânscrito e as línguas indo-europeias, do orientalista britânico Willian Jones (1746-1794), demonstra aquilo que poderia ser considerado um primeiro passo para a formação de uma área de conhecimento em Letras e Linguística. O avanço das pesquisas na área, segundo Dortier, dá-se com a gramática comparada e, posteriormente a linguística comparada, o que mais tarde seria reformulada pela perspectiva sincrônica e estruturalista da língua, feita por Ferdinand de Saussure (1857-1913), em seus cursos na Universidade de Genebra entre 1907 e 1910. Uma área de conhecimento constitui-se a partir do conjunto de pesquisas com tradição institucional e acadêmica, validada em congressos científicos, em publicações e, também, pelo financiamento de agências de fomento à pesquisa.

Letras e Linguística, enquanto uma área de conhecimento, no contexto nacional, encontra-se estritamente atrelada à criação de cursos de graduação e pós-graduação. Se o primeiro curso de graduação em Letras surge em 1934 na Universidade de São Paulo (USP), 24 anos após Saussure ministrar seu Cours de linguistique générale, a pós-graduação ainda esperaria mais 30 anos para começar a se estruturar. Em que pese o fato de a primeira tese de doutorado em Letras na USP ter sido defendida em 1942, a pós-graduação, como um sistema nacional de nucleação de pesquisadores e formação acadêmica começa a se estruturar no Brasil a partir do Parecer 1977/1965, de Newton Sucupira. Consequentemente, é no final da década de 60 que começa a ser consolidado um quadro de pesquisadores e cientistas da área de Letras e Linguística. Na USP, uma das instituições pioneiras na formação em pós-graduação da área, as primeiras dissertações em Teoria Literária e Literatura Comparada e Letras Modernas tiveram suas defesas no ano de 1967 (ALMEIDA, 2017).

O fato de hoje existir uma área de Letras e Linguística (ou Linguística e Literatura como sugere a reformulação mais recente da Coordenação de Aperfeiçoamento de Pessoal de Nível Superior (CAPES)) em departamentos, programas de pós-graduação, pró-reitorias de pesquisa e em agências de fomento, não quer dizer que o financiamento necessário ao desenvolvimento do trabalho esteja assegurado ou sempre tenha existido. Tomando como exemplo o caso de uma das principais agências federais de fomento à pesquisa, o Conselho Nacional de Desenvolvimento Científico e Tecnológico (CNPq), a proposição de ações programadas envolvendo a educação e a cultura, o que aproximou as ciências Humanas e Sociais Aplicadas de um tratamento mais próximo da chamada "ciências duras", ocorreu somente no apagar das luzes da repressão militar, sob a presidência de Lynaldo Albuquerque. 
É também nessa época que o III Plano Básico de Desenvolvimento Científico e Tecnológico, que cobria o período de 1980 a 1985, amplia as áreas dos Comitês Assessores. ${ }^{1}$

Olhando para essa trajetória, parece que o Estado tem oferecido poucas aberturas para a compreensão de um fazer científico que não seja o das chamadas "ciências duras". O equívoco reside no fato de que uma definição de ciência não pode estar reduzida à escolha do objeto que se pesquisa ou a uma contraposição de fundamentação metodológica entre pensamento empírico-indutivo e crítico-analítico. Isso não quer dizer que o método seja imune à validação de projeto feita pelos pares, apenas reitera que os mecanismos de problematização e desenvolvimento, teorização e análise, avaliação dos resultados e da produção do pesquisador e questões de ordem ética são entendidos de maneira diferente pelas áreas de conhecimento.

Não se pode definir um cientista pelo resultado esperado de sua pesquisa. Em outras palavras, ciência não compreende apenas a descoberta de vacinas ou experiências de modificação genética de sementes, ela engloba um amplo conjunto de saberes e, também, de ignorâncias próprias da natureza humana. Como afirma o divulgador científico Stuart Firestein (2019), a ciência deveria ser entendida mais como um catálogo de ignorâncias do que como a história da evolução humana. E essa afirmação parece ser plausível na medida em que descobertas podem implicar a invalidação de teses precedentes, ou, ainda, ser provocadas por novos desafios sobre aquilo que é desconhecido pelas pessoas ou por acontecimentos com os quais elas não sabem como lidar - por exemplo, a pandemia do coronavírus.

Se o principal combustível para o conhecimento advém da ignorância, o modus operandi do fazer científico não deveria estar focado na provocação da ciência como geração de um bem ou um produto utilitário, mas sim no aprofundamento daquilo do que é desconhecido. Para um cientista melhorar as condições de vida, criar plantas resistentes a pragas, propor formas de energia limpa ou alternativas de despoluição do planeta, há toda uma gama de conhecimentos de diferentes áreas agindo por detrás de sua descoberta.

A crônica do sapo levitador sobre Andre Geim é bastante ilustrativa nesse sentido. Esse físico, naturalizado holandês, ganhou o prêmio IgNobel, conferido às pesquisas mais bizarras da academia em 2000, por usar imãs para fazer levitar um sapo. A pesquisa de Geim não foi considerada relevante pela própria comunidade científica naquele momento. Mas foi a junção de sua experiência com a de outros cientistas que acabou produzindo a levitação magnética, hoje largamente empregada no transporte ferroviário em muitos países. Seu experimento com o sapo, o levou a receber o Nobel da Física em 2010. A palavra conhecimento possui uma origem latina que significa o saber que se constrói com alguém. Por isso, não se faz ciência sem partir de algum saber existente. Os governos mais autoritários tendem a exigir da comunidade científica resultados que sejam a criação de produtos que gerem divisas. Utilizamse deste argumento para pressionar a produção de uma ciência de resultados com possibilidade de aplicação direta no mercado. No mais, os conhecimentos que não atingem às demandas imediatas com resultados rentáveis são tratados como ricerca inutile. $\mathrm{O}$ exemplo do sapo de Geim pode ser lido como uma fábula moderna, cuja moral é de que as coisas inúteis serão de grande utilidade um dia.

Retomando Firestein:

Ir atrás da ignorância costuma produzir invenções maravilhosas. Mas a tentativa de tomar atalhos, provocar um curto-circuito no processo indo diretamente à aplicação, raramente produz algo de valor. Temos como exemplo, o enorme volume de trabalho despendido na tentativa de fazer computadores conversarem, como se isso não

\footnotetext{
${ }^{1}$ Ver a esse respeito o depoimento do presidente publicado na Revista Inovação, da Unicamp (ALBUQUERQUE, 2004).
} 
passasse de um problema de programação e não fosse uma profunda questão da neurociência cognitiva $(2019$, p. 54).

Os resultados atribuídos à ciência fundamentam sua origem na aplicação de uma diversidade de conhecimentos e de modalidades de pesquisa, no aprofundamento de estudos sobre coisas, fenômenos e acontecimentos. Entender as áreas de conhecimento de modo disjuntivo certamente não será a melhor via para encontrar respostas que ajudem a aliviar a ignorância com a qual sempre conviveu e conviverá a raça humana. Todas as áreas de conhecimento têm relevância e desempenham um papel para a compreensão, em suas múltiplas dimensões, da vida e da natureza humana no planeta. A departamentalização do saber e das disciplinas reinante nas universidades pode ser uma das principais responsáveis pela atrofia de uma prática transversal e transdisciplinar do conhecimento. E essa tradição, de certa maneira, tem levado a uma incompreensão sobre o que os cientistas estão produzindo em suas respectivas áreas.

Pesquisadores das humanidades não são menos cientistas porque pesquisam culturas, linguagens e línguas, ou se interessam mais por livros do que por periódicos, ou escrevem mais ensaios, ou porque simplesmente deixaram de usar jaleco em seus ambientes de trabalho. Desconsiderar o pesquisador das humanidades como um cientista ou como aquele que produz uma "ciência menor" influencia, incisivamente, na decisão de como serão aplicados os minguados recursos para a pesquisa. Quem já participou de um comitê de assessoramento de alguma agência de fomento, ou foi representante em alguma comissão orçamentária de uma universidade, sabe do jogo de poder operado entre as áreas de conhecimento na disputa de quem fica com o melhor quinhão da planilha orçamentária. Isso, que mais parece uma estratégia de sobrevivência em época de guerra, chama-se, na verdade, "política científica", uma arte que passa despercebida para muitos cientistas. Engajar-se no debate da política científica implica chamar o cientista para a responsabilidade sobre os rumos que a ciência está tomando. Considerando que a ciência é uma poderosa ferramenta de transformação, os cientistas podem tanto ser estimulados a pensar alternativas para a diminuição da desigualdade no mundo, como servir cegamente aos imperativos do mercado.

O conflito mais recente, que atravessa o tema da política científica, centra-se nas portarias do Ministério da Ciência, Tecnologia, Inovações e Comunicações (MCTIC) n. 1.122 e 1.329, publicadas em março de 2020. Sem adentrar nos detalhes e motivações ideológicas por detrás de suas publicações, enquanto a primeira categoricamente alija as humanidades de qualquer possibilidade de recursos, a segunda afirma que elas poderão ser contempladas, desde que seus projetos tenham uma interface com as áreas tecnológicas.

Com elas, o governo propõe a transformação de uma política científica de Estado em um falso programa racional, que visa a produzir um conjunto de resultados almejados. As portarias sinalizam para um iminente retrocesso da abertura do $\mathrm{CNPq}$ para as humanidades, conquistada a duras penas em 1980. Chamam a atenção os evidentes equívocos refletidos na busca de atalhos para gerar produtos e serviços tecnológicos e, ao mesmo tempo, diminuir o importante conjunto de saberes gerados com as pesquisas básicas das humanidades. A estimular projetos de pesquisa tecnológicos, o MCTIC despreza modelos mais amplos de compreensão e funcionamento dos fenômenos a serem investigados no âmbito das ciências. Em síntese, as portarias buscam prever um elenco de ignorâncias a serem sanadas, mas desconsideram o fato de que as ignorâncias são imprevisíveis e que, por esse motivo, as pesquisas consideradas menos importantes podem se tornar as mais interessantes da noite para o dia.

A política científica atua num complexo sistema de produção de conhecimento que implica, além da destinação de recursos, a forma como serão avaliados os resultados e, também, os pesquisadores que aplicam para os editais. A base dessa avaliação está sacramentada no 
famigerado aforismo publish or perish, que norteia a carreira acadêmica. O problema é que o publish supervalorizado ameaça levar a ciência ao perish, por meio de um contraditório sistema de avaliação que, como observa Antonio Banfi (2014), foi responsável pela criação de "monstros numéricos". Como observa o professor de direito italiano, a quantidade de artigos, livros e apresentações serviriam para justificar os recursos investidos na pesquisa. Na prática, instituiu-se um tipo de avaliação que privilegia o desempenho por meio da bibliometria.

O corolário foi que o sistema de avaliação e de julgamento de propostas das agências de fomento acionou o gatilho para o chamado "produtivismo" entre os cientistas, provocando no meio acadêmico uma corrida para publicação de artigos e disseminação em eventos científicos. Nas agências de fomento brasileiras é possível observar um fenômeno semelhante ao descrito por Banfi em relação às agências europeias: a necessidade de combater e descartar a proliferação de produtos gerados pelas pesquisas, que já foram bastante apreciados no sistema de avaliação.

No Relatório de Avaliação Quadrienal (2017), que engloba o período de avaliação da área de Linguística e Literatura entre 2013 e 2016, a equipe de coordenadores da área na CAPES mal esconde o espanto provocado pela produção dos seus pares, no tocante à apresentação de trabalhos:

\footnotetext{
Nessa quadrienal (2017), a produção técnica teve um tratamento diferenciado e é importante que isso tenha continuidade no quadriênio que já teve início. É importante que a produção técnica da Área passe para um processo de estratificação, considerando os diferentes produtos, e que se valorize menos, deixe a apresentação de trabalhos em eventos, algo assustador devido à quantidade: foram mais de 30 mil apresentações de trabalho ao longo do quadriênio (BRASIL, 2017, p. 3 - o negrito é meu).
}

Fazendo coro ao documento de área, o relatório de avaliação do Plano Nacional de Pós-Graduação (2011-2020), de 10/10/2018, enfatiza o mesmo problema por um outro viés, ao reiterar a necessidade de se combater o "produtivismo" na pós-graduação.

\footnotetext{
Prevalece uma concepção quantitativa na avaliação e o peso numérico estimula os programas a buscar uma prática "produtivista" exagerada que, em muitos casos, resulta em produção de baixa qualidade e de baixo impacto. O "produtivismo", quando transformado em cultura acadêmica no interior dos programas, tende a negligenciar a fundamental importância da formação do pós-graduando (BRASIL, 2018, p. 16).
}

O "produtivismo" é uma consequência direta de um modelo de avaliação pautado na quantificação de produtos gerados pela pesquisa. Ele tem um efeito radiativo sobre a política científica brasileira a qual, já debilitada pela falta de recursos, estimula ainda mais a inflação dos números entre pesquisadores. Nesse cenário, não deixa de ser comum a existência de critérios em editais que levam em conta à valorização da produção individual do pesquisador, por meio de um sistema de pesos no qual os mais experientes e com currículos robustos possuem maiores chances na disputa. Alia-se a isso, a falta de editais voltados para pesquisadores iniciantes que, com menos caminho andado e um conjunto de produções menos volumoso, muitas vezes não são atendidos em seus pedidos.

Ao ditar a ordem da produção científica, o produtivismo impõe a dinâmica dos prazos, ou seja, o tempo máximo para a entrega de relatórios, artigos, teses e dissertações, que vão se traduzir na avaliação de desempenho de um programa ou do próprio pesquisador. Nas humanidades, é importante reiterar, o prazo para o desenvolvimento de uma pesquisa inúmeras vezes inibe o aprofundamento necessário dos problemas investigados. Com isso, potencializa- 
se a reprodução de mitos científicos, dado que a aceleração não costuma condizer com a acuidade, o que pode levar a um ambiente propício à reprodução de afirmações enganosas.

A pressão de um currículo que torne o sujeito competitivo pode incitar o cientista a apresentar resultados ainda não consubstanciados em congressos ou com pouca profundidade de reflexão, o que provocaria um consequente esvaziamento das sessões de comunicação e desprestígio do pesquisador iniciante. Um dos problemas mais agudos de um currículo bastante fermentado é o autoplágio, em que artigos replicados intencionalmente com pequenas variações têm o intuito de obter uma melhor pontuação em concursos ou editais de financiamento. $\mathrm{O}$ autoplágio, sem levar em conta todas a implicações éticas contidas nele, expõe o óbvio ululante da ineficácia de um sistema avaliativo ancorado na bibliometria.

Mas se o produtivismo, surgido no interior das próprias agências de fomento, tornouse o principal problema do sistema avaliativo, a solução para avançar nesse processo ainda está longe de ser alcançada. Avaliar, como disse certa vez Renato Janine Ribeiro, à frente da Diretoria de Avaliação da CAPES, corresponde a atribuir um valor. E novamente as diferenças entre as áreas de conhecimento ressurgem, pois pensar critérios de avaliação corresponde, na prática, a definir um modus operandi comum às áreas. Impacto e inovação têm se tornados os novos avatares nos quais as agências têm se agarrado, na esperança de uma triunfal saída do problema do produtivismo.

Aqui, como em tudo que aspira a muita originalidade, não se reinventa a roda. $\mathrm{O}$ impacto, que vem sendo proposto como solução, nada mais é do que um outro tipo de sistema métrico de avaliação que indica a quantidade de citações do pesquisador. Uma pesquisa pode ser citada recorrentes vezes como um modelo de apresentação de resultados equivocados, oriundos da má interpretação das fontes e, ainda assim, impactará pela quantidade de citações.

A inovação apresenta-se como uma alternativa interessante, para critérios de julgamento, desde que a compreensão do que é, de fato, inovação não fique limitada à pesquisa das áreas tecnológicas, conforme priorizadas nas portarias do MCTIC. Isso não significa que os cientistas de Letras e Linguística não estejam estabelecendo parcerias profícuas com os das áreas tecnológicas. Linguistas têm sido cada vez mais imprescindíveis em projetos de linguagem de programação, as pesquisas em literatura têm trazido várias contribuições sobre jogos de videogame, e a linguística aplicada tem colaborado com a criação de ferramentas tecnológicas voltadas para o ensino, para lembrar aqui algumas ações. A inovação nesses casos é de ordem tecnológica também. Mas o escopo da inovação em Letras e Linguística é ainda maior. O Plano de Ação em Ciência, Tecnologia e Inovação para Ciências Humanas e Sociais desenhado pelo próprio MCTIC, e lançado em 2018, assinala a produção de inovação nas humanidades por meio de temas como: o desenvolvimento social sustentável, a internacionalização e a interdisciplinaridade, o combate à desigualdade, muitos dos quais já trabalhados em pesquisas da área de Letras e Linguística.

Talvez a área de Letras e Linguística projete timidamente para a sociedade, e até para a própria comunidade acadêmica, a relevância que possui para a formação do espírito, da pessoa humana e, até mesmo, da humanidade. Valores esses que já não servem mais à ciência pósmoderna, como bem observou Jean-François Lyotard (2009). Para traduzir essa contribuição em números, entre os anos de 1995 e 2014, os programas de pós-graduação em Letras e Linguística foram responsáveis pelo envio de maior número de alunos bolsistas para o exterior, o que reitera a sua importância na internacionalização. Ela foi a terceira área com maior número de doutores titulados e, também, com maior percentual de vínculo de docentes por programa. Não obstante ela ter sido a segunda maior área com número de alunos matriculados, foi a que menos recebeu cotas de bolsas (LIEVORE; PICININ; PILATTI, 2017). A pós-graduação continua sendo para a área de Letras e Linguística um campo de produção de conhecimento fundamental, apesar de não ser o único. Isso revela uma forma peculiar e talvez anacrônica, 
tanto na visão do Estado como do mercado, de desenvolvimento da ciência, na qual o conhecimento produzido encontra-se atrelado à formação e à capacitação do ser humano.

A fragmentação das metanarrativas, seguindo nas veredas já sinalizadas por Lyotard, tornou o conhecimento um tipo de consciência. A sociedade atual é um mundo constituído por comunidades virtuais e reais onde todos opinam e constroem suas verdades. As redes sociais podem ser o grande testemunho disso. A velocidade com que a informação é disseminada e reproduzida, faz com que a ciência seja tomada como um modo particular de organizar, estocar e distribuir informações. Logo, a atividade científica deixa de ser entendida a partir da sua práxis humanística, que investe na formação do sujeito e da pessoa humana. Se no Iluminismo, a ciência era uma atividade nobre e desinteressada com o objetivo de romper a ignorância e fazer crescer espiritualmente a nação, hoje, ela constitui-se num "valor de troca", desvinculada do cientista e do consumidor e submetida ao capital, ao estado, produzindo uma forma de saber para ser vendido.

Sendo parte das humanidades, Letras e Linguística sente o efeito imediato das transformações tecnológicas, que modificaram as formas de produzir e distribuir saberes. $\mathrm{Na}$ medida em que a ciência passa a ter um caráter utilitário (mais meio, entre outros, de produção de informação), ela é alçada a um tipo particular de mercadoria. Como resultado, a sociedade, consumidora de informações advindas de diversas fontes, passa a compreender a ciência mais um repositório de conteúdo, pressionando-a a atender o imperativo do consumo.

Isso justifica o fato de que as próprias associações e fóruns, cujo objetivo é o de defesa da ciência, às vezes sem perceber, acabam por atribuir um valor de uso para a ciência em seus discursos. Em junho de 2018, o Fórum Nacional de Pró-Reitores de Pesquisa e Pós-Graduação (FOPROP) publicou um documento de 9 páginas para subsidiar o debate eleitoral entre candidatos à presidência. $\mathrm{O}$ texto propunha-se a fazer uma análise de conjuntura das pesquisas no Brasil e não escondia seu objetivo principal de defesa de mais investimentos para a produção científica.

A argumentação seguia a linha de que os investimentos feitos em Ciência, Tecnologia e Inovação, via agências como Capes, CNPq e a Financiadora de Estudos e Projetos (FINEP), contribuíram para inserir o Brasil:

entre os líderes da produção de conhecimento em áreas fundamentais como exemplo: (i) a agricultura (produção de laranja, soja, frutas tropicais, cereais etc); (ii) a produção animal (carne bovina, suína e de frango); (iii) a automação (bancária, eleições e plantas industriais); (iv) a produção de aeronaves (Embraer); (v) a produção de biocombustíveis (etanol e biodiesel), petróleo (águas profundas), celulose e papel; (vi) a Odontologia; (vii) o controle biológico de insetos e a pesquisa sobre doenças tropicais e saúde pública, dentre muitas outras (2018, p. 3-4).

Não é necessário muito esforço interpretativo para entender que o FOPROP, que congrega cerca de 250 instituições, vale-se da lógica de que a ciência cumpre seu papel porque atende ao mercado, porque gera produtos inovadores, cuida da saúde e do bem-estar de todos e, como deixa subentendido, contribui para o fortalecimento da soberania nacional. Não há nenhuma inverdade nisso, mas a questão é o total apagamento das humanidades nesse documento, dos seus saberes e valores que não estão diretamente ligados à produção de commodities ou de outros bens de valor.

É preciso lembrar que, ao realizar uma ciência mais refratária aos interesses do Estado e do mercado, a área de Letras e Linguística reforça valores humanistas, por meio do enaltecimento da capacidade criativa, do pensamento crítico e de princípios democráticos. As humanidades estabelecem, desse modo, uma relação de saber em que pessoas são vistas como humanos vivendo em sociedade, com todos problemas que isso acarreta, e não como simples 
consumidores ávidos por mercadorias. Disso resulta uma conta cara aos cientistas da Letras e Linguística, que é assistir ao desaparecimento ou ao enfraquecimento de instituições ricas em conhecimento, mas de pouco "valor utilitário" para o mercado.

O incêndio do Museu Nacional do Brasil, no Rio de Janeiro em setembro de 2018, é bastante emblemático nesse sentido. Nele, havia um importante acervo com mapas e registros fonográficos de línguas indígenas, algumas delas já extintas, sob tutela do Mestrado Profissional em Linguística e Línguas Indígenas, que foi totalmente destruído. No Brasil, estima-se que $90 \%$ das línguas indígenas já se extinguiram, e segundo dados do Instituo de Estudos da Linguagem da Universidade Estadual de Campinas, outras 190 encontram-se em risco de extinção (MELITO, 2016).

A riqueza linguística poderia se desdobrar em outras pesquisas como as de plantas medicinais, culinária, diversidade de fauna e flora brasileiras, o que permitiria a aplicação de um conhecimento transdisciplinar, com cientistas de diferentes áreas. As comunidades aborígenes são um grande repositório de conhecimento, pouco explorado e com potencial para transformar as relações dos seres humanos com o planeta, cujos recursos têm sido explorados há, aproximadamente, $195 \mathrm{mil}$ anos. A memória linguística permite entender como se estabelece a ordem noética do sujeito, norteadora do princípio de sua ação no mundo. A compreensão da língua vai, portanto, além de seus elementos estruturantes e revela o modo de produzir cultura e pensar o mundo. Quando uma língua se extingue sem deixar registros não é apenas um repositório de informações que se perdeu para sempre, mas um pouco do passado e da história de cada um.

Enquanto o mercado pressiona as universidades e institutos de ciência a pesquisar temas de seu interesse, ou seja, que possam, num futuro próximo, "valer a pena o investimento", os fóruns, associações, sociedades, programas, docentes e discentes deve apelar para as práticas de resistência. Definitivamente, esse não é o momento para cair no canto da sereia: se a universidade e os cientistas aderirem a política científica que está sendo proposta pelo Estado, em pouco tempo estarão a serviço dos interesses do mercado. Constituirão um novo tipo de relação empresa-empregado destinada a transformar o saber numa refinada mercadoria para o consumo geral.

\section{REFERÊNCIAS}

ALBUQUERQUE, L. C. de. Ações Programadas do CNPq: III PBDCT (Plano Básico de Desenvolvimento Científico e Tecnológico: 1980-1985). Revista Brasileira de Inovação, Campinas, v. 3, n. 1, p. 201-211, Jan./Jun., 2004. Disponível em: https://periodicos.sbu.unicamp.br/ojs/index.php/rbi/article/view/8648896. Acesso em: 03 maio 2020.

ALMEIDA, Karla Nazareth Corrêa de. A pós-graduação no Brasil: história de uma tradição inventada. 2017. 213 p. Tese (Doutorado) - Universidade Estadual de Campinas, Faculdade de Educação, Campinas, SP. Disponível em: http://www.repositorio.unicamp.br/handle/REPOSIP/330450. Acesso em: 02 set. 2018.

BANFI, Antonio. Diamo i numeri alle scienze umane? Rischi e opportunità. In: BANFI, Antonio; FRANZINI, Elio; GALIMBERTI, Paola Galimberti. Non sparate sull'umanista. La sfida della valutazione. Milão: Guerini, 2014. 
BRASIL. MINISTÉRIO DA CIÊNCIA, TECNOLOGIA, INOVAÇÕES E COMUNICAÇÕES. Plano de Ação em Ciência, Tecnologia e Inovação para Ciências Humanas e Sociais. Brasília: Centro de Gestão e Estudos Estratégicos, 2018.

BRASIL. MINISTÉRIO DA CIÊNCIA, TECNOLOGIA, INOVAÇÕES E COMUNICAÇÕES. Portaria $\mathbf{n}^{\mathbf{0}} \mathbf{1 . 1 2 2}$, de 19 de março de 2020. Define as prioridades, no âmbito do Ministério da Ciência, Tecnologia, Inovações e Comunicações (MCTIC), no que se refere a projetos de pesquisa, de desenvolvimento de tecnologias e inovações, para o período 2020 a 2023. Brasília: MCTIC, ano 2020. Disponível em: https://www.mctic.gov.br/mctic/opencms/legislacao/portarias/Portaria_MCTIC_n_1122_de_1 9032020.html. Acesso em: 03 maio 2020.

BRASIL. MINISTÉRIO DA CIÊNCIA, TECNOLOGIA, INOVAÇÕES E COMUNICAÇÕES. Portaria no 1.329, de 27 de março de 2020. Altera a A Portaria $n^{\circ} 1.122$, de 19 de março de 2020, que define as prioridades, no âmbito do Ministério da Ciência, Tecnologia, Inovações e Comunicações (MCTIC), no que se refere a projetos de pesquisa, de desenvolvimento de tecnologias e inovações, para o período 2020 a 2023. Diário Oficial da União: MCTIC, Brasília: DO, ano 2020, v. 61A, n. 1, p. 1, 2020. Disponível em: http://www.in.gov.br/en/web/dou/-/portaria-n-1.329-de-27-de-marco-de-2020-250263672.

Acesso em: 03 maio 2020.

BRASIL. MINISTÉRIO DA EDUCAÇÃO. COORDENAÇÃO DE APERFEIÇOAMENTO DE PESSOAL DE NÍVEL SUPERIOR. Relatório da Avaliação Quadrienal 2017. Linguística e Literatura. Brasília: Diretoria de Avaliação/CAPES, 2017. Disponível em: https://www.capes.gov.br/images/documentos/Relatorios_quadrienal_2017/20122017-

letras_relatoriodeavalia\%C3\%A7\%C3\%A3o_quadrienal2017_final.pdf. Acesso em: 03 maio 2020 .

BRASIL. MINISTÉRIO DA EDUCAÇÃO. COORDENAÇÃO DE APERFEIÇOAMENTO DE PESSOAL DE NÍVEL SUPERIOR. Proposta de Aprimoramento do Modelo de Avaliação da PG. Documento Final da Comissão Nacional de Acompanhamento do PNPG 2011-2020. Brasília: CAPES, 2018. Disponível em: https://www.capes.gov.br/images/novo_portal/documentos/PNPG/2018_PNPG_CS_Avaliaca o_Final_10_10_18_CS_FINAL_17_55.pdf. Acesso em: 03 maio 2020.

DORTIER, Jean-François. Uma história das Ciências Humanas. Lisboa: Texto \& Grafia, 2009.

FIRESTEIN, Stuart. Ignorância: como ela impulsiona a ciência. Trad. Paulo Geiger. São Paulo: Cia. das Letras, 2019.

FOPROP. FÓRUM NACIONAL DE PRÓ-REITORES DE PESQUISA E PÓSGRADUAÇÃO. Subsídio para o debate com os candidatos. Eleições 2018. Brasília. FOPROP, 2018.

LIEVORE, Caroline; PICININ, Claudia Tania; PILATTI, Luiz Alberto. As áreas do conhecimento na pós-graduação stricto sensu brasileira: crescimento longitudinal entre 1995 e 2014. Ensaio: aval. pol. públ. Educ, vol.25, n. 94, p. 207-237, 2017. Disponível em: 
https://www.scielo.br/pdf/ensaio/v25n94/1809-4465-ensaio-25-94-0207.pdf. Acesso em: 03 maio 2020.

LYOTARD, Jean-François. A condição pós-moderna. Trad. Ricardo Correa Barbosa. 12. Ed., Rio de Janeiro: José Olympio, 2009.

MELITO, Fernando. Quase $\mathbf{9 0 \%}$ línguas indígenas brasileiras foram extintas e as que restam estão ameaçadas. Brasília: Portal EBC, 2016. Disponível em: https://www.ebc.com.br/cidadania/2016/04/de-1500-linguas-indigenas-no-descobrimentorestaram-181-todas-ameacadas-aponta. Acesso em: 03 maio 2020.

Recebido em: 03 de maio de 2020

Aceito em: 03 de maio de 2020

Publicado em Maio de 2020 